\title{
A Meta-Analysis of the Relationship between Children's Language Ability and Socio-Emotional Development
}

\author{
Young Tae Kim, Jin Kyong Kang, Jung A Kim \\ Department of Communication Disorders, Ewha Womans University, Seoul, Korea
}

Correspondence: Young Tae Kim, PhD Department of Communication Disorders, Ewha Womans University, 52 Ewhayeodae-gil, Seodaemun-gu, Seoul 03760, Korea Tel: $+82-2-3277-2120$

Fax: +82-2-3277-2122

E-mail: youngtae@ewha.ac.kr

Received: April 5, 2019

Revised: May 7, 2019

Accepted: May 7, 2019

This study was supported by the Ministry of Education of the Republic of Korea and the National Research Foundation of Korea (No. NRF2018S1A3A2075274, NRF-2018S1A3A2075274).
Objectives: Socio-emotion has important implications for child development. Language ability is closely related with socio-emotional development. This paper reviews studies of the relationship between language ability and socio-emotional development, and investigates the correlations between them and between their sub domains. Language ability is composed of receptive and expressive language and emergent literacy. Socio-emotional development includes externalizing and internalizing behaviors, social skills, and self-regulation. Methods: Twelve studies which meet the inclusive criteria were selected from 9 electronic databases (Academic Search Complete, PsycINFO, ERIC, PubMed, CINAHL Plus, ScienceDirect, RISS, DBpia, Kyobo Scholar). A systematic review of literature was carried out using meta-analysis (Comprehensive Meta-Analysis version 2 [CMA2]). Effect sizes were calculated using Fisher' Z. Results: There was a significant correlation between the two variables as a whole. In particular, there were significant correlations between receptive language and self-regulation, between expressive language and internalizing behavior, and between emergent literacy and self-regulation. However no significant correlation was found between all sub domains of language ability and externalizing behavior. Conclusion: These results suggest that language intervention methods need to be developed in order to decrease negative socio-emotions and to enhance positive ones.

Keywords: Receptive language, Expressive language, Emergent literacy, Socio-emotional development, Meta-analysis
사회정서발달은 심리사회적 측면에서 감정, 정서, 성격, 정체감, 대인관계 등의 발달적 변화를 포함하는 개념이다(Seo, 2014). 즉 인 간은 다른 사람과의 상호작용을 통해 자신이나 타인에 대한 인식 을 형성하고, 긍정적이거나 부정적인 감정의 변화 등을 경험하면서 조화롭거나 부적응적으로 살아가게 된다. 특히 학령전기의 사회정 서는 아동의 발달을 평가하기 위한 중요한 요인으로서 긍정적인 사 회정서가 발달할수록 초등학교로의 전환을 성공적으로 준비할 수 있다(Cohen \& Mendez, 2009). 또한 학령기 아동의 경우에도 사회 정서는 교사나 친구들과의 관계와 학업능력 등에도 영향을 주어 사회적 기술이 좋을수록 학교생활 만족도가 높게 된다(Longoria, Page, Hubbs-Tait, \& Kennison, 2009; Monopoli \& Kingston, 2012). 이러한 사회정서발달은 언어능력과 밀접한 관계가 있다(Clegg,
Law, Rush, Peters, \& Roulstone, 2015; Menting, Van Lier, \& Koot, 2011; Rose, Weinert, \& Ebert, 2018b). 왜냐하면 아이들은 주변 사 람들의 이야기를 듣거나 질문을 하면서 의사소통을 하고, 이를 통 해 다른 사람의 관점을 조망하고 사회적 기술을 발휘해 나가는 것 을 학습하기 때문이다. 예를 들어 SLI 아동의 경우 일반아동에 비해 좀 더 공격적이고, 협동성이 떨어지며, 분노와 같은 부정적 감정을 조절하는 데 어려움을 나타낸다고 했다(Fujiki, Brinton, \& Clarke, 2002).

언어능력과 사회정서발달의 관계에 관한 최근의 연구들을 살펴 보면 다음과 같다.

첫째, 수용언어능력과 사회정서발달의 관계에 대해서 살펴보면 유치원 아동의 낮은 수용언어 점수가 초등학교 때의 공격성을 예 
측하였으며(Menting et al., 2011), 초등학교 2학년 아동들의 수용 어휘능력과 외현적 행동은 부적인 상관관계를 나타낸다고 했다 (Monopoli \& Kingston, 2012). 수용 및 표현언어와사회정서발달의 관계를 종단 연구한 Rose 등(2018b)의 연구에서는 수용어휘 점수 가 공격행동, 적응행동, 자기조절 등의 사회정서와 유의미한 상관관 계를 나타냈다. Tan과 Dobbs-Oates (2013)의 연구에서도 학령전기 아동들의 수용언어능력이 과잉행동, 주의력 문제, 자기조절, 적응, 기능적 의사소통, 사회적 기술 등의 사회정서와 유의미한 상관관계 를 나타냈다. 그러나 Aro, Eklund, Nurmi와 Poikkeus (2012)의 연 구에서는 수용언어능력이 공격성이나 주의력 문제, 적응성, 사회적 기술 등의 사회정서와 유의미한 상관관계를 나타내지 않았다.

둘째, 표현언어능력과 사회정서발달의 관계를 볼 때, 언어로 표현 하는 데 어려움이 있는 아동들은 또래들과 상호작용하기 위하여 공격적 행동을 표출할 위험이 있다(Girard, Pingault, Doyle, Falissard, \& Tremblay, 2016, 2017). Rose 등(2018b)은 3세 때 표현언어능 력이 수용언어능력과 마찬가지로 7세 때 공격 행동, 적응행동, 자기 조절 등의 사회정서와 유의미한 상관관계를 나타냈다고 했다. Tan 과 Dobbs-Oates (2013)의 연구에서도 표현언어 점수가 내재적 행동, 주의력 문제, 자기조절, 적응성, 사회적 기술 등의 사회정서와 유의 미한상관관계를 나타냈다. 그러나 Fantuzzo, Bulotsky, McDermott, Mosca와 Lutz (2003)의 연구에서는 표현어휘 점수가 공격성, 문제 행동, 위축 등의 사회정서와 유의미한 상관을 나타내지 않았다.

셋째, 초기 문해능력과 사회정서발달의 관계에 대한 연구들은 많지 않은 편이며, Lonigan 등(1999)의 연구에 의하면 학령전기 아 동의 경우 인쇄물에 대한 지식과 관련된 초기 문해능력이 자기조 절 변수와 유의미한 상관관계를 나타냈고, 다른 사회정서 변수들, 즉 과잉행동, 문제행동, 사회적 기술과는 유의미한 상관을 나타내 지 않았다. Tan과 Dobbs-Oates (2013)의 연구에서는 알파벳 지식 이 자기통제, 사회적 기술의 사회정서 변수와 정적 상관관계가 있 는 것으로 나타났다.

위의 선행연구들에서는 사회정서와의 관계를 보기 위해 언어능 력을 수용언어, 표현언어, 초기 문해능력 등으로 구분하는 경향이 있다. 수용언어능력은 수용어휘력을 측정하거나(Monopoli \& Kingston, 2012; Rose et al., 2018b) 문법 및 구문이해능력을 측정하 였다(Aro et al., 2012; Fujiki et al., 2002). 표현언어능력은 표현어휘 력을 측정하거나(Fantuzzo et al., 2003; Stowe, Arnold, \& Ortiz, 1999) 문법 및 구문에 관한 표현능력(Fujiki et al., 2002; Lonigan et al., 1999), 낱말이름대기검사 등을 활용하여 측정하였다(Girard et al., 2016, 2017). 초기 문해능력은 알파벳지식, 인쇄물지식, 음운처 리능력 등을 측정하였다(Bornstein, Hahn, \& Putnick, 2016; Doc- toroff, Greer, \& Arnold, 2006). 사회정서발달의 주요 변수로는 외 현적 행동(externalizing behaviors), 내재적 행동(internalizing behaviors), 사회적 기술(social skills), 자기조절(self-regulation) 등이 있다. 외현적 행동은 공격성이나 과잉행동으로 인해 겉으로 드러나 는 정서 행동이다. 내재적 행동은 걱정이나 우울, 위축 등과 같이 드 러나지 않는 특성을 나타낸다. 사회적 기술은 적응, 애착, 기능적 의 사소통 등을 의미하며, 대인관계 기술이라고도 할 수 있다. 자기조 절은 정서 상태와 관련된 행동의 억제 및 촉진을 의미한다(Aro et al., 2012; Tan \& Dobbs-Oates, 2013).

언어능력과 사회정서발달의 관계에 관한 선행연구들을 살펴보 면 변수들을 측정하는 검사도구나 연구방법, 변수, 대상자 특성 등 의 차이로 인해 결과가 다양하게 나타나서 언어능력과 사회정서발 달의 전반적인 상관관계가 어느 정도인지를 파악하기 어렵다. 또한 대부분의 연구들이 언어능력과 사회정서발달 변수들을 부분적으 로 살펴보았기 때문에 언어능력별로 사회정서의 각 하위요인들과 구체적으로 어떠한 관계가 있는지를 보기 위해서는 두 변수의 하위 요인들을 체계적이고 종합적으로 분석할 필요성이 있다. 따라서 본 연구에서는 학령전기 및 학령기 일반아동들의 언어능력과 사회정 서발달의 관계를 살펴보기 위해 체계적 문헌분석 및 메타분석을 실시하였다. 선정된 연구들의 체계적 문헌분석을 통해 연구대상과 검사과제 등에 대한 질적 분석을 실시하였으며, 메타분석을 통해 서는 언어능력과 사회정서발달이 전반적으로 어떤 관계가 있는지 를 살펴보고, 각 변수의 하위요인들 간의 구체적인 상관관계도 분 석하고자 하였다. 각 하위요인 간의 관계를 분석하기 위해 언어능 력의 하위요인들은 수용언어, 표현언어, 초기 문해능력으로 나누고, 사회정서발달의 하위요인들은 외현적 행동, 내재적 행동, 사회적 기술, 자기조절로 구분하였다. 이에 따른 연구문제는 다음과 같다.

1. 언어능력과 사회정서발달은 어떠한 관계가 있는가?

2. 언어능력의 하위요인은 사회정서발달(외현적 행동, 내재적 행 동, 사회적 기술, 자기조절)과 어떠한 관계가 있는가?

2.1. 수용언어능력은 사회정서발달과 어떠한 관계가 있는가?

2.2. 표현언어능력은 사회정서발달과 어떠한 관계가 있는가?

2.3. 초기 문해능력은 사회정서발달과 어떠한 관계가 있는가?

\section{연구방법}

\section{문헌 검색}

아동의 언어능력과 사회정서발달의 관계에 관한 특성을 알아보 기 위해 2018년 11월 9일에 국내외 데이터베이스와 관련 논문의 참 고문헌을 통해 관련 논문들을 수집하였다. 국내(RISS, DBpia, 
Young Tae Kim, et al. • A Meta-Analysis of Children's Language Ability and Socio-Emotional Development

Kyobo Scholar) 및 국외(PsycINFO, Academic Search Complete, ERIC, PubMed, CINAHL Plus, ScienceDirect) 등 총 9개의 데이터 베이스에서 검색어("language ability AND [reading OR writing OR literacy] AND socioemotional development”)를 활용하여 검 색을 실시하였다.

\section{논문의 선정 기준}

분석 대상 논문을 선정하기 위하여 문헌 검색을 통해 Eric에서 2,528편, PsycINFO에서 570편, ScienceDirect에서 415편, Academic Search Complete에서 157편, PubMed에서 127편, CINAHL Plus 에서 99편, RISS, DBpia, Kyobo Scholar에서 1편으로 총 3,897편의 논문이 검색되었다. 최근 20년을 기준으로 하여 1998년부터 2018년 게재된 논문, full-text 이용 가능 여부, peer reviewed journal 논문,
영어로 작성된 논문을 기준으로 545편을 선정하였다. 이 중 중복된 논문 482 편을 제외하여 63편을 선정하였다. 포함 및 제외 기준을 적용하여 총 12 편을 분석 대상 논문으로 선정하였다. 분석 대상 논 문의 포함 기준으로는 (1) 아동을 대상으로 한 연구, (2) 언어(구어, 문어)변수와 사회정서 변수의 상관관계에 관한 연구, (3) 아동의 언 어능력에 관한 연구, (4) 아동의 사회정서발달에 관한 연구를 분석 대상 논문으로 포함하였으며, 이러한 기준에 부합되지 않은 연구 들은 분석 대상에서 제외하였다. Figure 1과 Table 1에 논문 선정 과 정에 대한 순서도 및 선정 및 제외 기준을 각각 제시하였다.

\section{자료의 분석}

자료의 코딩 및 분석

연구자, 게재연도, 대상 정보 및 표본 크기, 검사 종류, 변수 등을

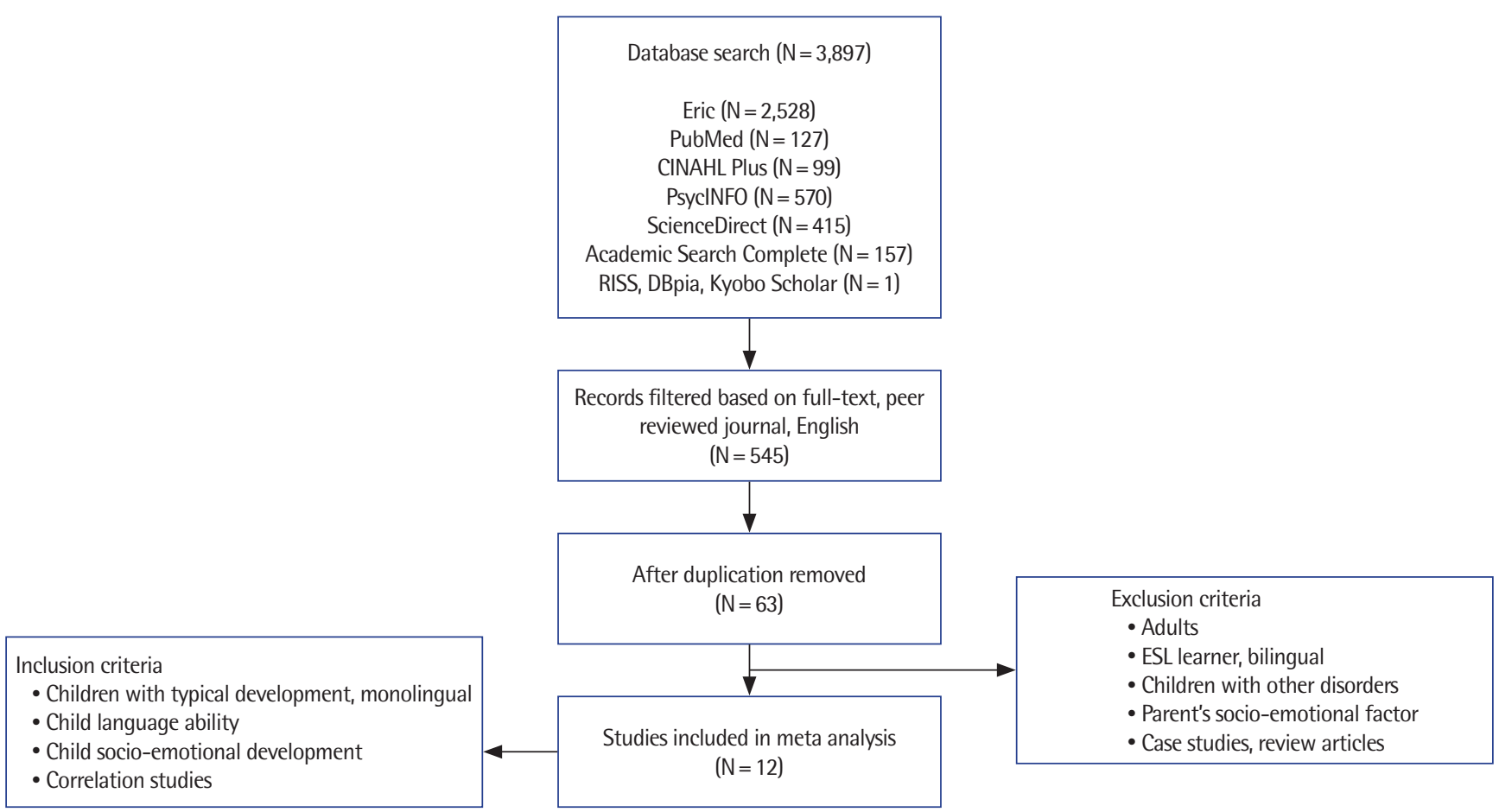

Figure 1. Flowchart of studies included from search.

Table 1. Criteria for inclusion and exclusion

\begin{tabular}{|c|c|c|}
\hline & Inclusion & Exclusion \\
\hline Participants & Children with typical development, monolingual & $\begin{array}{l}\text { Adults, Children with other disorders, } \\
\text { ESL learner, bilingual }\end{array}$ \\
\hline Factors & $\begin{array}{l}\text { Child language ability } \\
\text { Child socio-emotional development }\end{array}$ & Parent's socio-emotional factor \\
\hline Design & Correlation studies & Case studies, review articles \\
\hline Outcome measures & $\begin{array}{l}\text { Language ability (receptive language, expressive language, emergent literacy), socio-emotional } \\
\text { development (externalizing behavior, internalizing behavior, social skills, self-regulation) }\end{array}$ & Non-relevant measures \\
\hline
\end{tabular}


데이터로 입력하였다. 변수는 언어능력과 사회정서발달이며, 두 변 수의 관계에 대한 효과 크기는 선정된 연구들에서 상관계수 $r$ 과 표 본크기를 사용하여 산출하였다. 학령전기 및 학령기 일반 아동의 언어능력과 사회정서발달의 관계를 분석하기 위해 각 변수들을 하 위영역으로 나누어 살펴보았다. 언어능력의 하위영역(수용언어, 표 현언어, 초기 문해능력)과 사회정서발달의 하위영역(외현적 행동, 내재적 행동, 사회적 기술, 자기조절)의 상관관계에 관한 효과크기 를 알아보고자 하였다.

체계적 문헌분석은 선정된 문헌들을 고찰하여 연구대상과 검사 과제 등을 중심으로 질적 분석을 하였으며, 메타분석은 Comprehensive Meta-Analysis (CMA 2.0)를 사용하여 분석하였다. 두 변 수의 하위영역 간의 상관계수 $r$ 은 정규분포를 따르는 Fisher's Z로 전환하였으며, $95 \%$ 신뢰구간 및 유의수준 .05를 기준으로 효과크 기의 유의성을 검증하였다. 또한 연구들의 통계적 이질성 여부를 확인하기 위해 동질성 검정을 수행한 결과, $\mathrm{Q}=796.61$ ( $p<.001), \mathrm{I}^{2}$ 은 $94.6, \tau^{2}$ 은 .032 로 본 연구에서 선정된 연구들의 대상 및 방법 등 이 이질적인 것으로 나타났다. 따라서 연구들의 다양성을 반영하 여 결과값을 무선효과모형(random-effects model)으로 제시하였 다(Kim, Oh, Choi, Kim, \& Sung, 2018; Oh, Eom, Park, \& Sung, 2016).

\section{대상 연구들의 질 평가}

본 연구에 포함된 논문들의 질적 평가를 위해 Gersten 등(2005) 의 필수적 질적 지표(Essential Quality Indicators)를 사용하였다. 이 척도에서는 연구 대상자에 대한 정보, 연구방법, 연구에서의 측 정 변인 그리고 데이터 분석과 관련한 항목들에 대해 3점 척도로 평가한다. 본 연구에 포함된 총 12 개 연구의 질적 수준을 평가한 결 과, 데이터분석 관련 지표를 제외한 나머지 지표들은 모두 평균3점 으로 나타났다. Menting 등(2011)의 연구는 데이터 분석에서 각 변 수들의 상관계수를 표로 제시하지 않아 평균 2.5점으로 평가되었다.

\section{출판편향 검증}

선정된 연구들의 출판편향 오류를 검증하기 위하여 funnel plot 을 통해 좌우대칭성 여부를 시각적으로 확인한 결과(Figure 2), 소 수의 연구들이 비대칭성을 유발한 것으로 관찰되어 비대칭성에 대 한 통계적 유의성을 분석하기 위해 Egger의 회귀분석을 실시하였 다. 분석 결과, bias $=1.38(t=1.77, p>.05)$ 로 나타나, 본 연구에 포함 된 연구들에 대한 출판편향은 통계적으로 유의하지 않음을 확인 하였다.

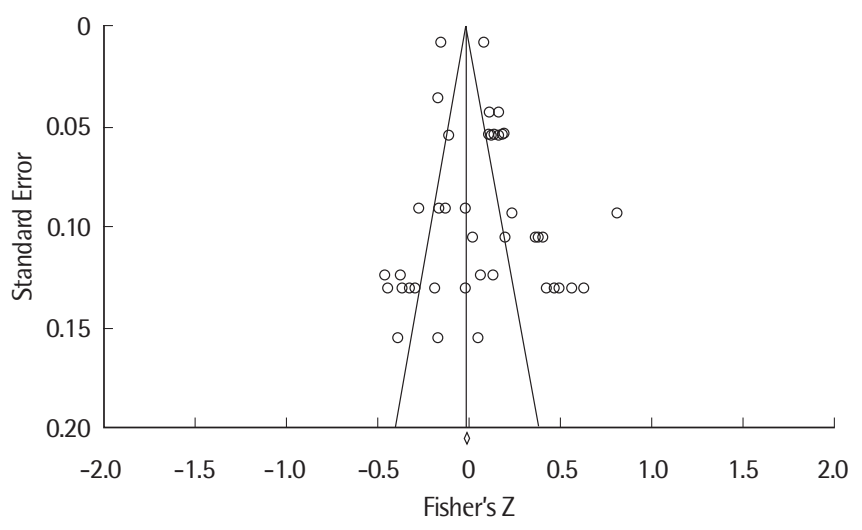

Figure 2. Funnel plot of standard error by Fisher's Z.

\section{신뢰도 평가}

언어병리학 박사과정 연구자 2 인이 분석에 포함된 12 편의 논문 에 대하여 각 논문의 정보 및 통계값을 코딩하여 효과크기를 산출 한 후 항목별 결과를 비교하였고, 평가자 간 신뢰도는 $100 \%$ 였다.

\section{연구결과}

\section{연구의 질적 분석}

연구 대상

본 연구에 포함된 12 개의 논문은 만 4 세에서 8 세까지의 일반아 동 총 30,470 명을 대상으로 하였다. 이 중 7 개의 연구는 단일 연령 에 대한 횡단연구로 이루어졌으며 5 개의 연구는 3 세의 언어능력과 5세의 사회정서발달(Girard et al., 2016, 2017; Rose, Lehrl, Ebert, \& Weinert, 2018a), 3세의 언어능력과 7.5세의 사회정서발달(Rose et al., 2018b), 5세의 언어능력과 8세의 사회정서발달(Aro et al., 2012) 에 관한 종단연구로 이루어졌다. 각 연구별로 대상자들의 모국어는 영어(8편), 독일어(2편), 핀란드어(1편), 네덜란드어(1편)로 총 4가지 의 언어였다.

\section{연구 과제}

언어능력을 측정하는 과제는 크게 수용언어, 표현언어, 초기 문 해능력으로 분류하였다. 수용언어를 측정하는 데에 사용된 과제 는 수용어휘력, 구문 및 문법의 이해, 지시 이해가 있었고, 표현언어 를 측정하는 데에 사용된 과제로는 표현어휘력과제, 문장 산출과 제, 구문 및 문법 표현과제가 있었다. 초기 문해능력을 측정하는 데 에 사용된 과제는 음운기억, 음운인식, 음운인출 등과 관련된 음운 처리과제와 인쇄물 인식능력, 인쇄물지식, 알파벳지식, 가정에서의 문해활동에 관한 체크리스트 과제가 있었다. 언어능력을 측정하는 
Young Tae Kim, et al. • A Meta-Analysis of Children's Language Ability and Socio-Emotional Development

과제에는 대부분 표준화된 검사도구의 전체 혹은 하위영역 일부가 사용되었다. PPVT (Peabody Picture Vocabulary Test; Dunn, \& Dunn, 1997)가 수용어휘능력을 측정하는 데에 사용되었고, BNT (Boston Naming Test; Kaplan, Goodglass, \& Weintraub, 1983), EOWPVT-R (The Expressive One-Word Picture Vocabulary TestRevised; Gardner, 1990), EVT (Expressive Vocabulary Test; Williams, 1997)가 표현어휘력을 측정하는 데 사용되었다. NEPSY (Korkman, Kirk, \& Kemp, 1998), BAS-II (British Ability Scale II; Elliott, Smith, \& McCulloch, 1997), WPPS-R (Wechsler, 1995), The McCarthy Scales of Children's Abilities (McCarthy, 1972), TOLD-GU (Test of Language Development- Grammatical Understanding; Newcomer \& Hammill, 1988), ITPA-GC (Illinois Test of Psycholinguistic Abilities-Grammatical Closure; Kirk, McCarthy, \& Kirk, 1968), SETK3-5 (Comprehensive German Language Development Test for 3- to 5-year-old children, Sprachentwicklungstest für 3 bis 5-jährige; Grimm, 2001). TROG-D (Test for the Reception of Grammar-D; Bishop, 1989)가 수용 및 표현언어능력을 측정하는 데에 사용되었으며, 초기 문해능력은 TERA-3 (Test of Early Reading Ability third edition; Kim Reid, Hresko, \& Hammill, 2001)를 사용하여 측정하였다.

사회정서능력을 측정하는 과제로는 ASPI (Adjustment Scales of Preschool Intervention; Lutz, Fantuzzo, \& McDermott, 2002), ERC (The Emotion Regulation Checklist; Shields \& Cicchetti, 1997),
BASC-2 (Behavior Assessment System for Children second edition; Reynolds \& Kamphaus, 2004), DECA (Devereux Early Childhood Assessment; LeBuffe \& Naglieri, 1999), CPSCS (Levine, Elzey, \& Lewis, 1969) 등과 같은 표준화된 검사도구가 사용되었으며, CTRS (The Conners Teacher Rating Scale; Conners, 1994), The Kohn Social Competence Scale (Kohn \& Rosman, 1972), PBSI (Problem Behavior at School Interview; Erasmus Medical Center, 2004) 등 과 같이 기존연구에서 개발된 검사문항이 사용되기도 하였다. 이 때에는 내적일치 신뢰도의 신뢰계수(Cronbach's alpha)가 제시되 었다. 분석 문헌에 관한 구체적인 내용을 Appendix 1에 제시하였다.

\section{메타분석 결과}

언어능력과 사회정서발달의 관계

아동의 언어능력과 사회정서발달의 관계를 분석한 결과, $\mathrm{Z}=$ $.073, p<.05,95 \%$ 신뢰구간[.012, .134]로 나타나 언어능력과 사회정 서발달 간에 유의미한 상관이 있는 것으로 나타났다. 메타분석 결 과는 Table 2와 Figure 3에 제시하였다.

Table 2. Effect size of overall outcome measures between language development and socio-emotional development

\begin{tabular}{lcccc}
\hline & \multirow{2}{*}{ Fisher's Z } & \multicolumn{2}{c}{$95 \% \mathrm{Cl}$} & \\
\cline { 3 - 4 } & & Lower limit & Upper limit & \\
\hline Overall & .073 & .012 & .134 & .018 \\
\hline
\end{tabular}

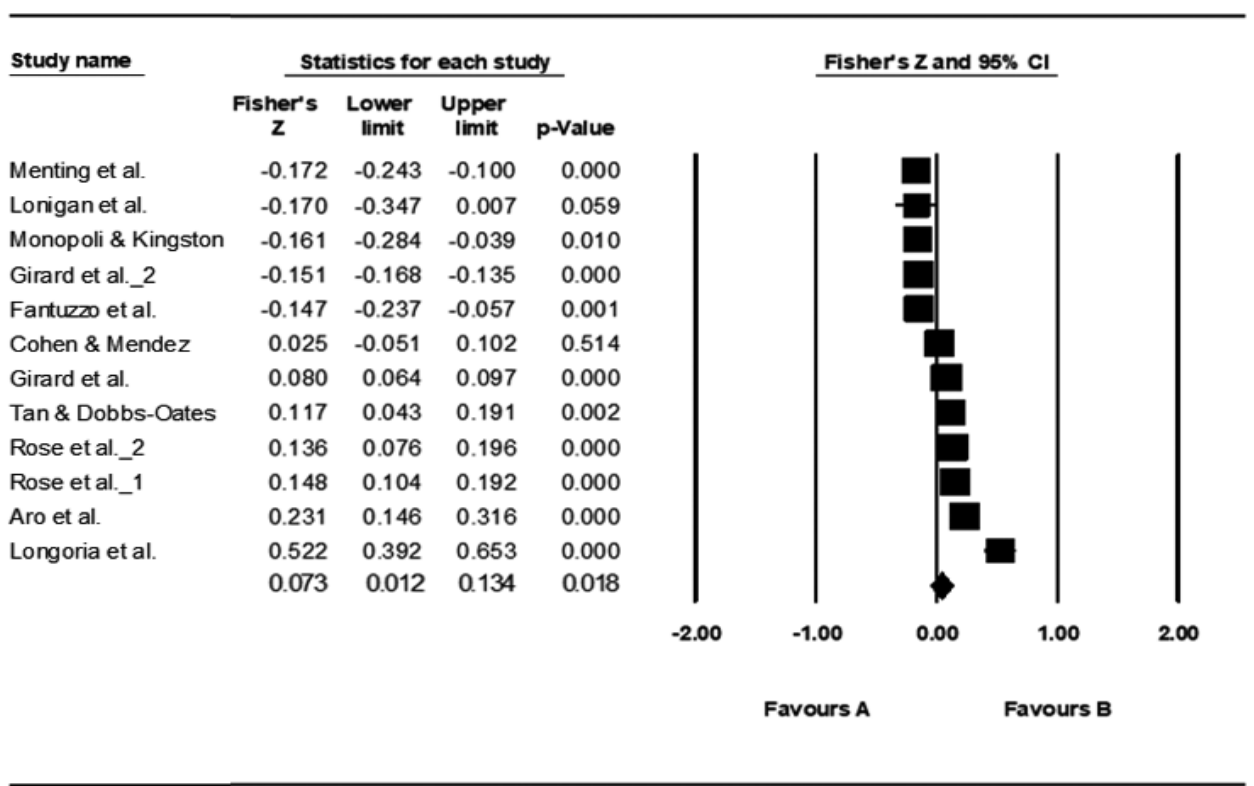

Figure 3. Forest plot of overall outcome measures between language development and socio-emotional development. 
주요 측정치별 관계

아동의 언어능력과 사회정서발달의 관계를 분석하기 위해 언어 능력의 3 가지 하위영역(수용언어, 표현언어, 초기 문해능력)과 사회 정서발달의 4 가지 하위영역(외현적 행동, 내재적 행동, 사회적 기술, 자기조절)에 대하여 총 11 개의 상관관계를 분석하였다. 각 측정치 에 대한 효과크기를 분석한 결과는 Table 3에 제시하였다.

먼저 수용언어와 외현적 행동의 상관관계를 분석한 결과, $\mathrm{Z}=$ $-.059, p>.05,95 \%$ 신뢰구간은 [-.271, .152]으로 유의한 상관관계가 나타나지 않았다. 수용언어와 내재적 행동의 상관관계 분석에서는 $\mathrm{Z}=-.109, p<.01,95 \%$ 신뢰구간[-.191, -.027]로 유의한 부적 상관관

Table 3. Effect size of sub-measures between language development and socio-emotional development.

\begin{tabular}{lcccc}
\hline & \multirow{2}{*}{ Fisher's Z } & \multicolumn{2}{c}{$95 \%$ Cl } & p-value \\
\cline { 3 - 4 } & & Lower limit & Upper limit & \\
\hline RL \& EB & -.059 & -.271 & .152 & .581 \\
RL \& IB & -.109 & -.191 & -.027 & .009 \\
RL \& SS & .192 & -.039 & .422 & .104 \\
RL \& SR & .207 & .101 & .312 & .000 \\
EL \& EB & -.062 & -.199 & .075 & .372 \\
EL \& IB & -.205 & -.353 & -.058 & .006 \\
EL \& SS & .325 & .102 & .549 & .004 \\
EL \& SR & .183 & -.025 & .395 & .085 \\
Literacy \& EB & -.155 & -.525 & .215 & .411 \\
Literacy \& SS & .191 & .113 & .269 & .000 \\
Literacy \& SR & .208 & .011 & .405 & .038 \\
\hline
\end{tabular}

$\mathrm{RL}=$ receptive language; $\mathrm{EL}=$ expressive language; $\mathrm{EB}=$ externalizing behavior; $\mathrm{IB}=$ internalizing behavior; $\mathrm{SS}=$ social skills; $\mathrm{SR}=$ self-regulation.
계가 나타났다(Figure 4). 수용언어와 사회적 기술의 상관관계를 분석한 결과 $\mathrm{Z}=.192, p>.05,95 \%$ 신뢰구간[-.039, .422]로 유의하지 않았다. 수용언어와 자기조절의 관계를 분석한 결과 $\mathrm{Z}=.207$, $p<.001,95 \%$ 신뢰구간[.101, .312]로 유의한 정적 상관관계가 나타 났다(Figure 5). 즉 수용언어와 사회정서발달의 관계의 하위영역 중 내재적 행동과 자기조절의 관계에서 유의미한 상관관계가 나타났 으나, 수용언어와 외현적 행동 및 사회적 기술의 관계에서는 유의 미한 상관관계가 나타나지 않았다.

표현언어와 외현적 행동의 상관관계를 분석한 결과 $\mathrm{Z}=-.062$, $p>.05,95 \%$ 신뢰구간[-.199, .075]로 유의한 상관관계는 나타나지 않았다. 표현언어와 내재적 행동의 상관관계를 살펴본 결과, $\mathrm{Z}=$ $-.205, p<.05,95 \%$ 신뢰구간[-.353, -.058]로 유의한 부적 상관관계 가 나타났다(Figure 6). 표현언어와 사회적 기술의 상관관계를 분석 한 결과 $\mathrm{Z}=.325, p<.05,95 \%$ 신뢰구간[.102, .549]로 유의한 정적 상관관계가 나타났다(Figure 7). 표현언어와 자기조절의 관계를 분 석한 결과 $\mathrm{Z}=.183, p>.05,95 \%$ 신뢰구간[-.025, .395]로 유의한 상 관관계는 나타나지 않았다. 즉 표현언어는 사회정서발달의 하위영 역 중 내재적 행동과 사회적 기술의 관계에서는 유의미한 상관관계 를 보였으나 표현언어와 외현적 행동 및 자기 조절에서는 유의미한 상관은 나타나지 않았다.

초기 문해능력과 외현적 행동의 상관관계를 분석한 결과 $\mathrm{Z}=$ $-.155, p>.05,95 \%$ 신뢰구간[-.525, .215]로 유의한 상관관계가 나타 나지 않았다. 초기 문해능력과 내재적 행동의 상관관계에 관한 문 헌은 Tan과 Dobbs-Oates (2013)의 연구 이외에는 검색되지 않아 분석에서 제외하였다. 초기 문해능력과 사회적 기술의 상관관계를

\begin{tabular}{|c|c|c|c|c|c|}
\hline \multirow[t]{2}{*}{ Study name } & \multirow[t]{2}{*}{ Subgroup within study } & \multicolumn{4}{|c|}{ Statistics for each study } \\
\hline & & $\begin{array}{c}\text { Fisher's } \\
\mathbf{Z}\end{array}$ & $\begin{array}{l}\text { Lower } \\
\text { limit }\end{array}$ & $\begin{array}{l}\text { Upper } \\
\text { limit }\end{array}$ & p-Value \\
\hline Fantuzzo et al. & 2.000 & -0.277 & -0.457 & -0.097 & 0.0 \\
\hline Tan \& Dobbs-Oates & 2.000 & -0.019 & -0.276 & 0.238 & 0.8 \\
\hline Cohen \& Mendez & 2.000 & -0.110 & -0.219 & -0.002 & 0.0 \\
\hline \multirow[t]{2}{*}{ Monopoli \& Kingston } & 2.000 & 0.131 & -0.114 & 0.376 & 0.2 \\
\hline & & -0.109 & -0.191 & -0.027 & 0.0 \\
\hline
\end{tabular}

Figure 4. Forest plot of Fisher's Z between receptive language and internalizing behavior. 


\begin{tabular}{|c|c|c|c|c|c|c|c|c|c|}
\hline \multirow[t]{2}{*}{ Study name } & \multirow[t]{2}{*}{$\underline{\text { Subgroup within study }}$} & \multicolumn{4}{|c|}{ Statistics for each study } & \multicolumn{4}{|c|}{ Fisher's $\mathrm{Z}$ and $95 \% \mathrm{Cl}$} \\
\hline & & $\begin{array}{c}\text { Fisher's } \\
\mathbf{Z}\end{array}$ & $\begin{array}{c}\text { Lower } \\
\text { limit }\end{array}$ & $\begin{array}{l}\text { Upper } \\
\text { limit }\end{array}$ & p-Value & & & & \\
\hline Monopoli \& Kingston & 4.000 & 0.060 & -0.185 & 0.305 & 0.631 & & & & 1 \\
\hline Rose et al._1 & 4.000 & 0.141 & 0.034 & 0.248 & 0.010 & & & & \\
\hline Cohen \& Mendez & 4.000 & 0.161 & 0.053 & 0.270 & 0.003 & & & & \\
\hline Aro et al. & 4.000 & 0.364 & 0.157 & 0.572 & 0.001 & & & & \\
\hline \multirow[t]{4}{*}{ Tan \& Dobbs-Oates } & 4.000 & 0.427 & 0.170 & 0.685 & 0.001 & & & 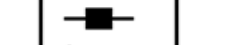 & \\
\hline & & 0.207 & 0.101 & 0.312 & 0.000 & & & & \\
\hline & & & & & & -2.00 & -1.00 & 0.00 & 2.00 \\
\hline & & & & & & & Favours A & Favours B & \\
\hline
\end{tabular}

Figure 5. Forest plot of Fisher's Z between receptive language and self-regulation.

\begin{tabular}{|c|c|c|c|c|c|c|c|c|c|c|}
\hline \multirow[t]{2}{*}{ study name } & \multirow[t]{2}{*}{ Subgroup within study } & \multicolumn{4}{|c|}{ Statistics for each study } & \multicolumn{5}{|c|}{ Fisher's $\mathrm{Z}$ and $95 \% \mathrm{Cl}$} \\
\hline & & $\begin{array}{c}\text { Fisher's } \\
\mathbf{Z}\end{array}$ & $\begin{array}{c}\text { Lower } \\
\text { limit }\end{array}$ & $\begin{array}{l}\text { Upper } \\
\text { limit }\end{array}$ & p-Value & & & & & \\
\hline Tan \& Dowrs-Oates & 6.000 & -0.295 & -0.553 & -0.038 & 0.025 & & & & & \\
\hline \multirow[t]{4}{*}{ Fantuzzo et al. } & 6.000 & -0.161 & -0.341 & 0.018 & 0.078 & & & & & \\
\hline & & -0.205 & -0.353 & -0.058 & 0.006 & & & & & \\
\hline & & & & & & -2.00 & -1.00 & 0.00 & 1.00 & 2.00 \\
\hline & & & & & & & Favours A & & Favours B & \\
\hline
\end{tabular}

Figure 6. Forest plot of Fisher's Z between expressive language and internalizing behavior.

\begin{tabular}{|c|c|c|c|c|c|c|c|c|c|}
\hline \multirow[t]{2}{*}{ Study name } & \multirow[t]{2}{*}{ Subgroup within study } & \multicolumn{4}{|c|}{ Statistics for each study } & \multicolumn{4}{|c|}{ Fisher's $\mathrm{Z}$ and $95 \% \mathrm{Cl}$} \\
\hline & & $\begin{array}{c}\text { Fisher's } \\
\mathbf{z}\end{array}$ & $\begin{array}{l}\text { Lower } \\
\text { limit }\end{array}$ & $\begin{array}{l}\text { Upper } \\
\text { limit }\end{array}$ & p-Value & & & & \\
\hline Girard et al. & 7.000 & 0.080 & 0.064 & 0.097 & 0.000 & & & & 1 \\
\hline Rose et al._1 & 7.000 & 0.141 & 0.033 & 0.249 & 0.010 & & & & \\
\hline Aro et al. & 7.000 & 0.195 & -0.012 & 0.403 & 0.065 & & & & \\
\hline Tan \& Dobbs_Oates & 7.000 & 0.466 & 0.209 & 0.723 & 0.000 & & & & \\
\hline \multirow[t]{4}{*}{ Longoria et al. } & 7.000 & 0.811 & 0.626 & 0.995 & 0.000 & & & & \\
\hline & & 0.325 & 0.102 & 0.549 & 0.004 & & & & \\
\hline & & & & & & -2.00 & -1.00 & 0.00 & 2.00 \\
\hline & & & & & & & Favours A & Favours B & \\
\hline
\end{tabular}

Figure 7. Forest plot of Fisher's Z between expressive language and social skills. 


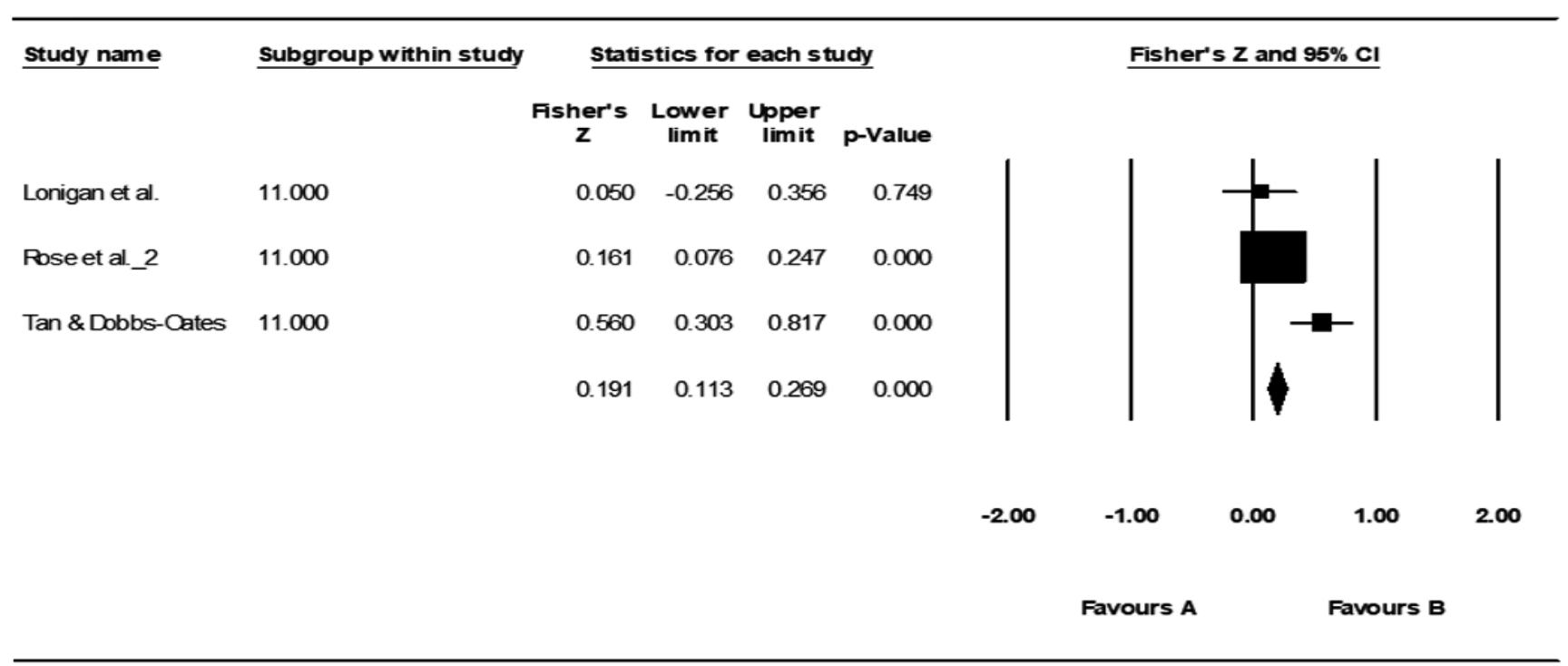

Figure 8. Forest plot of Fisher's Z between literacy and social skills.

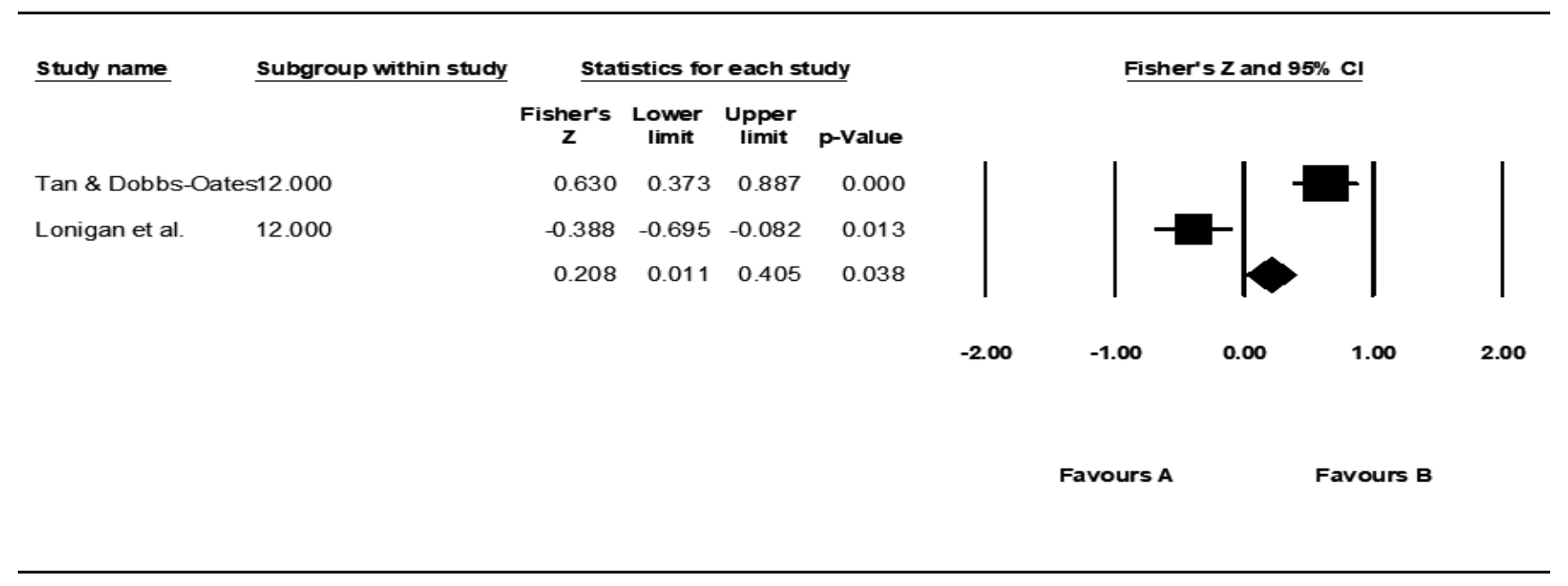

Figure 9. Forest plot of Fisher's Z between literacy and social skills.

분석한 결과 $\mathrm{Z}=.191, p<.001,95 \%$ 신뢰구간[.113, .269]로 유의한 정적 상관관계가 나타났다(Figure 8). 초기 문해능력과 자기조절의 관계를 분석한 결과 $\mathrm{Z}=.208, p<.05,95 \%$ 신뢰구간[.011, .405]로 유 의한 정적 상관관계가 나타났다(Figure 9). 즉 초기 문해능력은 사 회정서발달의 하위영역 중에서 사회적 기술과 자기 조절과의 관계 에서는 유의미한 상관이 있었으나 문해능력과 외현적 행동은 유의 미한 상관이 없는 것으로 나타났다.

\section{논의 및 결론}

본 연구는 만 4 세부터 8 세까지의 일반아동의 언어능력과 사회정
서발달의 관계에 관한 특성을 알아보기 위하여 언어능력의 하위요 인들과 사회정서발달의 하위요인들 간의 상관관계를 분석하였다. 언어능력의 하위요인으로는 수용언어능력, 표현언어능력, 초기 문 해능력을 살펴보았고, 사회정서발달의 하위요인으로는 외현적 행 동, 내재적 행동, 사회적 기술, 자기조절을 살펴보았다. 연구의 포함 및 제외 기준에 따라 선정된 총 12 개의 연구를 메타분석한 결과, 수 용언어능력은 내재적 행동 및 자기조절과 유의미한 상관관계를 보 였다. 표현언어능력은 내재적 행동 및 사회적 기술과 유의미한 상관 관계를 보였다. 마지막으로 초기 문해능력은 사회적 기술 및 자기조 절과 유의미한 상관관계를 보였다. 사회정서변인 중 외현적 행동은 전체 언어변인 중 어느 하위영역과도 유의미한 상관관계를 보이지 
Young Tae Kim, et al. • A Meta-Analysis of Children's Language Ability and Socio-Emotional Development

않았다.

본 연구의 결과에 따른 논의는 다음과 같다. 첫째, 아동의 언어능 력과 사회정서발달의 관계는 전반적으로 유의미한 상관관계가 있 는 것으로 나타났다. 이는 여러 선행연구들에서 아동의 언어발달 이 사회정서발달에 영향을 주거나(Bornstein, Hahn, \& Putnick, 2016; Clegg et al., 2015; Huttunen \& Välimaa, 2010; Lee \& Rescorla, 2008), 사회정서발달이 언어발달을 예측하거나(Schmitt, Justice, \& O'Connell, 2014; Smith, Borkowski, \& Whitman, 2008), 두 영역이 상관관계에 있음을 주장한 것(Aram \& Aviram, 2009; Bosacki, 2012; Kubicek \& Emde, 2012)과 같은 맥락에 있는 것으로 볼 수 있다.

둘째, 본 연구에서 수용언어는 사회정서발달의 하위요인인 내재 적 행동과는 유의미한 부적 상관관계를 보였고, 자기조절과는 유의 미한 정적 상관을 보였다. 이는 언어이해력이 높을수록 덜 우울하 고 덜 위축되며, 감정이나 행동도 더 잘 조절할 수 있음을 의미한다. 즉 타인의 말을 잘 이해하는 아동은 위축되어 혼자 놀기보다는 또 래와 어울릴 수 있고, 자신의 분노나 충동성 또는 욕구를 더 잘 조 절할 가능성이 있다고 볼 수 있다. 또한 우울하고 위축되거나 불안 한 내재적 특성을 보이는 아동은 낮은 언어이해력을 나타낼 수 있 는데, 이는 우울하고 위축된 내재적 특성으로 인하여 또래와 어울 리거나 활동에 참여하는 데에 제한됨으로써 언어이해력을 발달시 키기 위하여 필요한 기회들이 줄어들 가능성이 있기 때문이다(Aro et al., 2012; Fujiki et al., 2002; Rose et al., 2018b).

셋째, 표현언어는 사회정서발달의 하위요인 중 내재적 행동과는 유의미한 부적 상관관계를 보였으며, 사회적 기술과는 유의미한 정 적 상관을 보였다. 즉 언어표현을 잘 하는 아동은 언어이해력이 높 은 경우와 마찬가지로 위축되거나 우울하여 혼자 놀기보다는 또래 와 상호작용을 적극적으로 함으로써 적절한 사회적 기술을 발휘할 가능성이 높다. 마찬가지로 우울이나 불안의 정도가 낮은 아동들 은 또래와 어울리는 기회를 통해 언어표현력을 발달시켜 나갈 수 있을 것이다(Bouchard, Cloutier, Gravel, \& Sutton, 2008).

넷째, 초기 문해능력은 사회정서발달 중 사회적 기술 및 자기조 절과 유의미한 정적 상관관계를 보였다. 즉 읽기 및 쓰기의 초기 발 달이 원만하게 이루어진 아동은 또래 및 교사를 대할 때 적절한 사 회적 기술을 보이고, 감정이나 행동조절을 잘 할 수 있을 가능성이 높으며, 반대로 사회적 기술이 우수하고 감정이나 행동조절 및 욕 구지연을 잘 하는 아동은 읽기 및 쓰기 발달 또한 원만히 이루어질 가능성이 높다고 볼수 있다(Doctoroff et al., 2006).

다섯째, 본 연구에서는 사회정서발달의 요인 중 외현적 행동의 경우 수용 및 표현, 초기 문해능력 등 모든 언어능력의 하위요인들 과 유의미한 상관관계가 나타나지 않았다. 이는 공격행동, 방해행
동, 충동적 행동 등의 외현적 행동과 언어능력과의 관계를 다룬 기 존의 다수의 연구결과와는 상반된 결과이다(Doctoroff et al., 2006; Stowe et al., 1999). 이는 연령에 따른 차이로 설명해 볼 수 있다. Tan 과 Dobbs-Oates (2013)는 만 34-64개월 아동 61명을 대상으로 언 어능력(수용언어, 표현언어, 초기 문해능력)과 사회정서능력발달의 관계를 분석하기 위해 연령과 성별을 조절변수로 하여 중다회귀분 석을 실시하였다. 분석 결과, 수용언어능력 및 초기 문해능력과 사 회정서발달의 하위영역인 외현적 행동과의 관계에서 연령이 조절 변수로 작용하는 것으로 나타났다. 즉 연령이 증가함에 따라 부정 적인 정서행동인 외현적 행동이 수용언어 및 초기 문해능력에 미치 는 영향도 증가한다고 하였다. 만 3-5세 아동을 대상으로 4년간의 종단연구를 실시한 Arnold 등(1999)의 연구에서도 연령이 초기 문 해능력과 사회정서발달의 관계와 상호작용하는 것으로 나타났는 데, 연령이 증가함에 따라 공격성과 초기 문해능력의 부적 상관관 계가 높아지는 것으로 나타났다. 즉, 언어능력과 외현적 행동의 관 계는 연령에 따라 차이가 있을 수 있는데, 본 연구에서는 선정된 연 구들의 대상아동들이 만 3세부터 8세까지 혼재되어 있었으며, 총 12 개의 분석 대상 연구 중 5 개는 횡단연구로 이루어져 있으므로 언 어발달과 사회정서발달의 관계에 대하여 연령에 따른 변화의 양상 을 보여주는 데에는 한계가 있는 것으로 보인다.

또한 언어발달과 외현적 행동의 관계에 대한 상반된 연구결과는 성별에 의한 차이로 설명할 수 있다(Bouchard et al., 2008; Doctoroff et al., 2006; Rose et al., 2018b; Stowe et al., 1999; Tan \& DobbsOates, 2013). Doctoroff 등(2006)의 연구에서는 초기 문해능력이 낮은 남아의 경우 공격성과 관련이 있었지만 초기 문해능력이 낮은 여아의 경우에는 유의미한 관계가 없는 것으로 나타났다. Rose 등 (2018b)의 연구에서도 만 3-7세 일반아동을 대상으로 수용 및 표현 언어와 자기조절, 협력행동, 공격행동의 관계를 살펴본 결과, 언어 능력과 사회정서발달의 관계에서 성차가 조절변수의 역할을 하였 다. 남아의 수용언어능력은 사회정서발달의 외현적 행동인 공격행 동에 영향을 주었고, 여아의 경우에는 표현언어능력이 외현적 행동 에 영향을 준 것으로 나타났다. Stowe 등(1999)의 연구에서도 언어 능력이 낮은 남아가 언어능력이 낮은 여아보다 문제행동을 더 일으 킨다고 했다. 이러한 연구결과들을 볼 때 언어능력과 외현적 행동 간의 관계를 보기 위해서는 성별을 고려할 필요가 있으나 분석 대 상 논문 중 대부분에서 성차에 대한 상관계수를 추정할 수 없었기 때문에 본 연구에서는 성차를 분석하지 않았다. 이로 인해 두 변수 간의 관계가 유의미하지 않게 나온 것으로 볼 수 있다.

본 연구의 제한점 및 제언은 다음과 같다. 첫째, 연령과 성별이 언 어능력 및 사회정서발달의 관계에서 조절변수가 될 수 있다는 선행 
연구들을 고려할 때 대상아동의 연령과 성별에 따른 차이를 구체 적으로 살펴볼 필요가 있다. 둘째, 본 연구에서는 일반아동을 대상 으로 한 연구만을 분석 대상으로 삼았으나 이후 장애군에 따른 언 어능력 및 사회정서발달의 관계에 대하여 분석할 필요가 있다. 셋 째, 본 연구에서는 언어능력과 사회정서발달의 상관관계를 다룬 연 구들을 분석의 대상으로 선정하였으나 회귀분석이나 경로분석을 이용한 연구들도 분석의 대상으로 하여 사회정서발달을 설명하고 예측하는 언어능력의 특성에는 어떤 요소들이 있는지를 살펴본다 면 이후 언어중재 프로그램을 개발하고 적용하는 데에 보다 다각적 인 정보를 제공할 수 있을 것이다.

\section{REFERENCES}

Aram, D., \& Aviram, S. (2009). Mothers' storybook reading and kindergartners' socioemotional and literacy development. Reading Psychology, 30(2), 175-194.

Arnold, D. H., Ortiz, C., Curry, J. C., Stowe, R. M., Goldstein, N. E., Fisher, P. H., ... \& Yershova, K. (1999). Promoting academic success and preventing disruptive behavior disorders through community partnership. Journal of Community Psychology, 27(5), 589-598.

Aro, T., Eklund, K., Nurmi, J. E., \& Poikkeus, A. M. (2012). Early language and behavioral regulation skills as predictors of social outcomes. Journal of Speech, Language, and Hearing Research, 55(2), 395-408.

Bishop, D. V. (1989). Test for the reception of grammar (TROG) version 2. London: Medical Research Council.

Bornstein, M. H., Hahn, C. S., \& Putnick, D. L. (2016). Stability of core language skill across the first decade of life in children at biological and social risk. Journal of Child Psychology and Psychiatry, 57(12), 1434-1443.

Bosacki, S. (2012). Socioemotional competence, self-perceptions, and receptive vocabulary in shy Canadian children. International Electronic Journal of Elementary Education, 4(3), 573-591.

Bouchard, C., Cloutier, R., Gravel, F., \& Sutton, A. (2008). The role of language skills in perceived prosociality in kindergarten boys and girls. European Journal of Developmental Psychology, 5(3), 338-357.

Clegg, J., Law, J., Rush, R., Peters, T. J., \& Roulstone, S. (2015). The contribution of early language development to children's emotional and behavioural functioning at 6 years: an analysis of data from the Children in Focus sample from the ALSPAC birth cohort. Journal of Child Psychology and Psychiatry, 56(1), 67-75.

Cohen, J. S., \& Mendez, J. L. (2009). Emotion regulation, language ability, and the stability of preschool children's peer play behavior. Early Education and Development, 20(6), 1016-1037.

Conners, C. K. (1994). The Conners Rating Scales: use in clinical assessment, treatment planning and research. In M. Maruish (Ed.), Use of psychological testing for treatment planning and outcome assessment (pp. 550-578). Hillsdale, NJ: Erlbaum Associates.

Doctoroff, G. L., Greer, J. A., \& Arnold, D. H. (2006). The relationship between social behavior and emergent literacy among preschool boys and girls. Journal of Applied Developmental Psychology, 27(1), 1-13.

Dunn, L. M., \& Dunn, L. M. (1997). Peabody Picture Vocabulary Test, third edition. Circle Pines, MN: American Guidance Service.

Elliott, C. D., Smith, P., \& McCulloch, K. (1997). British Ability Scales II: technical manual. London: NFER-Nelson Publishing Company.

Erasmus Medical Center. (2004). Problem behavior at school interview. Rotterdam, the Netherlands: Department of Child and Adolescent Psychiatry, Erasmus Medical Center.

Fantuzzo, J., Bulotsky, R., McDermott, P., Mosca, S., \& Lutz, M. N. (2003). A multivariate analysis of emotional and behavioral adjustment and preschool educational outcomes. School Psychology Review, 32(2), 185-203.

Fujiki, M., Brinton, B., \& Clarke, D. (2002). Emotion regulation in children with specific language impairment. Language, Speech, and Hearing Services in Schools, 33(2), 102-111.

Gardner, M. F. (1990). Expressive One-Word Picture Vocabulary Test, revised (EO-WPVT-R). Novato, CA: Academic Therapy Publications.

Gersten, R., Fuchs, L. S., Compton, D., Coyne, M., Greenwood, C., \& Innocenti, M. S. (2005). Quality indicators for group experimental and quasiexperimental research in special education. Exceptional Children, 71(2), 149-164.

Girard, L. C., Pingault, J. B., Doyle, O., Falissard, B., \& Tremblay, R. E. (2016). Developmental associations between conduct problems and expressive language in early childhood: a population-based study. Journal of Abnormal Child Psychology, 44(6), 1033-1043.

Girard, L. C., Pingault, J. B., Doyle, O., Falissard, B., \& Tremblay, R. E. (2017). Expressive language and prosocial behaviour in early childhood: longitudinal associations in the UK Millennium Cohort Study. European Journal of Developmental Psychology, 14(4), 381-398.

Grimm, H. (2001). SETK 3-5: Sprachentwicklungstest für drei- bis fünfjährige Kinder [Language development test for 3- to 5-year-olds]. Göttingen, Germany: Hogrefe.

Huttunen, K., \& Välimaa, T. (2010). Parents' views on changes in their child's 
Young Tae Kim, et al. • A Meta-Analysis of Children's Language Ability and Socio-Emotional Development

communication and linguistic and socioemotional development after cochlear implantation. Journal of Deaf Studies and Deaf Education, 15(4), 383-404.

Kaplan, E., Goodglass, H., \& Weintraub, S. (1983). Boston naming test. Philadelphia, PA: Lea \& Febiger.

Kim, J. A., Oh, S. J., Choi, E., Kim, Y. T., \& Sung, J. E. (2018). A meta-analysis of eye-tracking studies on text processing in children with reading disabilities. Communication Sciences \& Disorders, 23(3), 597-608.

Kim Reid, D., Hresko, W. P., \& Hammill, D. D. (2001). TERA-3: Test of Early Reading Ability. Los Angeles, CA: Western Psychological Services.

Kirk, S. A., McCarthy, J. J., \& Kirk, W. D. (1968). Illinois test of psycholinguistic abilities. Urbana, IL: University of Illinois Press.

Kohn, M., \& Rosman, B. L. (1972). A social competence scale and symptom checklist for the preschool child: factor dimensions, their cross-instrument generality, and longitudinal persistence. Developmental Psychology, 6(3), 430.

Korkman, M., Kirk, U., \& Kemp, S. L. (1998). NEPSY: a developmental neuropsychological assessment. San Antonio, TX: The Psychological Corporation.

Kubicek, L. F., \& Emde, R. N. (2012). Emotional expression and language: a longitudinal study of typically developing earlier and later talkers from 15 to 30 months. Infant Mental Health Journal, 33(6), 553-584.

LeBuffe, P. A., \& Naglieri, J. A. (1999). The Devereux Early Childhood Assessment. Lewisville, NC: Kaplan Press Publishing.

Lee, E. C., \& Rescorla, L. (2008). The use of psychological state words by late talkers at ages 3, 4, and 5 years. Applied Psycholinguistics, 29(1), 21-39.

Levine, S., Elzey, F. F., \& Lewis, M. (1969). California preschool social competency scale. Palo Alto, CA: Consulting Psychologists Press.

Longoria, A. Q., Page, M. C., Hubbs-Tait, L., \& Kennison, S. M. (2009). Relationship between kindergarten children's language ability and social competence. Early Child Development and Care, 179(7), 919-929.

Lonigan, C. J., Bloomfield, B. G., Anthony, J. L., Bacon, K. D., Phillips, B. M., \& Samwel, C. S. (1999). Relations among emergent literacy skills, behavior problems, and social competence in preschool children from low-and middle-income backgrounds. Topics in Early Childhood Special Education, 19(1), 40-53.

Lutz, M. N., Fantuzzo, J., \& McDermott, P. (2002). Multidimensional assessment of emotional and behavioral adjustment problems of low-income preschool children: development and initial validation. Early Childhood Research Quarterly, 17(3), 338-355.

McCarthy, D. (1972). McCarthy scales of children's abilities. Cleveland, OH:
Psychological Corporation.

Menting, B., Van Lier, P. A., \& Koot, H. M. (2011). Language skills, peer rejection, and the development of externalizing behavior from kindergarten to fourth grade. Journal of Child Psychology and Psychiatry, 52(1), 72-79.

Monopoli, W. J., \& Kingston, S. (2012). The relationships among language ability, emotion regulation and social competence in second-grade students. International Journal of Behavioral Development, 36(5), 398-405.

Newcomer, P. L., \& Hammill, D. D. (1988). Test of language development-primary (2nd ed.). Austin, TX: PRO-ED.

Oh, S. J., Eom, B., Park, C., \& Sung, J. E. (2016). Treatment efficacy of semantic feature analyses for persons with aphasia: evidence from meta-analyses. Korean Journal of Communication Disorders, 21(2), 310-323.

Reynolds, C. R., \& Kamphaus, R. W. (2004). BASC-2: Behavior Assessment System for Children. Circle Pines, MN: American Guidance Service.

Rose, E., Lehrl, S., Ebert, S., \& Weinert, S. (2018a). Long-term relations between children's language, the home literacy environment, and socioemotional development from ages 3 to 8. Early Education and Development, 29(3), 342-356.

Rose, E., Weinert, S., \& Ebert, S. (2018b). The roles of receptive and productive language in children's socioemotional development. Social Development, 27(4), 777-792.

Schmitt, M. B., Justice, L. M., \& O’Connell, A. (2014). Vocabulary gain among children with language disorders: contributions of children's behavior regulation and emotionally supportive environments. American Journal of Speech-Language Pathology, 23(3), 373-384.

Seo, Y. (2014). An effect of persistence and degree of exposure to school violence victimization experience on socioemotional development in youths. Korean Journal of Youth Studies, 21(6), 223-253.

Shields, A., \& Cicchetti, D. (1997). Emotion regulation among school-age children: The development and validation of a new criterion Q-sort scale. Developmental Psychology, 33(6), 906-916.

Smith, L. E., Borkowski, J. G., \& Whitman, T. L. (2008). From reading readiness to reading competence: the role of self-regulation in at-risk children. Scientific Studies of Reading, 12(2), 131-152.

Stowe, R. M., Arnold, D. H., \& Ortiz, C. (1999). Gender differences in the relationship of language development to disruptive behavior and peer relationships in preschoolers. Journal of Applied Developmental Psychology, 20(4), 521-536.

Tan, M., \& Dobbs-Oates, J. (2013). Relationship between emergent literacy and early social-emotional development in preschool children from low- 


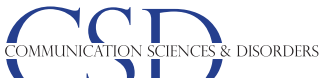

income backgrounds. Early Child Development and Care, 183(11), 15091530.

Wechsler, D. (1995). WPPSI-R: Wechslerin älykkyystestistö esikouluikäisille

[Wechsler Preschool and Primary Scale of Intelligence-Revised]. Helsinki,
아동의 언어능력과 사회정서발달의 관계에 관한 메타분석 - 김영태 외 Finland: Psykologien kustannus.

Williams, K. T. (1997). Expressive vocabulary test. Circle Pines, MN: American Guidance Service. 
Young Tae Kim, et al. • A Meta-Analysis of Children's Language Ability and Socio-Emotional Development CCMMUNICATION SCIENCES\& DISORDERS

Appendix 1. Summary of studies included in the meta-analysis

\begin{tabular}{|c|c|c|c|c|c|c|c|c|}
\hline \multirow{2}{*}{ No. } & \multirow{2}{*}{ Study } & \multirow{2}{*}{ Age (yr) } & \multirow{2}{*}{ N } & \multirow{2}{*}{$\begin{array}{l}\text { Native } \\
\text { language }\end{array}$} & \multicolumn{2}{|c|}{ Language development } & \multicolumn{2}{|c|}{ Socioemotional development } \\
\hline & & & & & Content & Outcome measure & Content & Outcome measure \\
\hline 1 & Aro et al. (2012) & $5-8$ & 92 & Finnish & $\begin{array}{l}\text { Receptive vocabulary, morphological } \\
\text { skills, comprehension of } \\
\text { instructions, expressive } \\
\text { vocabulary, sentence production, } \\
\text { rating of productive language }\end{array}$ & $\begin{array}{l}\text { PPVT-R, BNT, } \\
\text { NEPSY, WPPSI-R }\end{array}$ & $\begin{array}{l}\text { Attention problems, aggression, } \\
\text { hyperactivity, adaptability, social } \\
\text { skills }\end{array}$ & BASC \\
\hline 2 & $\begin{array}{l}\text { Cohen \& Mendez } \\
\text { (2009) }\end{array}$ & 4.5 & 331 & English & Receptive vocabulary & PPVT & Self-regulation & ERC \\
\hline 3 & $\begin{array}{l}\text { Fantuzzo et al. } \\
(2003)\end{array}$ & 4.4 & 122 & English & $\begin{array}{l}\text { Receptive vocabulary, expressive } \\
\text { vocabulary }\end{array}$ & $\begin{array}{l}\text { PPVT-3, } \\
\text { EOWPVT-R }\end{array}$ & $\begin{array}{l}\text { Externalizing behavior (aggressive, } \\
\text { Inattentive/hyperactive), } \\
\text { internalizing behavior (oppositional, } \\
\text { withdrawn/low energy, socially } \\
\text { reticent) }\end{array}$ & ASPI \\
\hline 4 & $\begin{array}{l}\text { Girard et al. } \\
\text { (2017) }\end{array}$ & $3-5$ & 14,004 & English & Expressive language & BAS & Social skills (prosocial behavior) & SDO \\
\hline 5 & $\begin{array}{l}\text { Girard et al. } \\
\text { (2016) }\end{array}$ & $3-5$ & 14,004 & English & Expressive language & BAS & $\begin{array}{l}\text { Externalizing behavior (temper } \\
\text { tantrum, obedient, fights, spiteful, } \\
\text { argumentative) }\end{array}$ & SDQ \\
\hline 6 & $\begin{array}{l}\text { Longoria et al. } \\
\text { (2009) }\end{array}$ & 4.81 & 116 & English & $\begin{array}{l}\text { Receptive language (vocabulary, } \\
\text { word knowledge), expressive } \\
\text { language (word fluency) }\end{array}$ & $\begin{array}{l}\text { PPVT, McCarthy } \\
\text { Scales of } \\
\text { Children's Abilities }\end{array}$ & Social competency & CPSCS \\
\hline 7 & $\begin{array}{l}\text { Lonigan et al. } \\
\text { (1999) }\end{array}$ & 4 & 44 & English & $\begin{array}{l}\text { Receptive vocabulary, receptive } \\
\text { grammar, expressive vocabulary, } \\
\text { expressive grammar, phonological } \\
\text { sensitivity, lexical access, } \\
\text { phonological memory, print } \\
\text { knowledge }\end{array}$ & $\begin{array}{l}\text { PPVT, EOWVT-R, } \\
\text { TOLD-GU, ITPA-GC }\end{array}$ & $\begin{array}{l}\text { Hyperactivity, conduct problem, } \\
\text { inattention, social competence, } \\
\text { rule following }\end{array}$ & $\begin{array}{l}\text { CTRS, } \\
\text { Kohn Social } \\
\text { Competence } \\
\text { Scale }\end{array}$ \\
\hline 8 & $\begin{array}{l}\text { Menting et al. } \\
\text { (2011) }\end{array}$ & 6 & 759 & Dutch & Receptive vocabulary & PPVT & $\begin{array}{l}\text { Externalizing behavior (conduct } \\
\text { problems, oppositional defiant } \\
\text { problems), peer rejection }\end{array}$ & PBSI \\
\hline 9 & $\begin{array}{l}\text { Monopoli \& } \\
\text { Kingston } \\
\text { (2012) }\end{array}$ & 7.5 & 67 & English & Receptive vocabulary & PPVT & $\begin{array}{l}\text { Externalizing problem, internalizing } \\
\text { problem, school problem, adaptive } \\
\text { skill, lability, emotion regulation }\end{array}$ & ERC, BASC \\
\hline 10 & $\begin{array}{l}\text { Rose et al. } \\
\text { (2018a) }\end{array}$ & $3.5-7$ & 340 & German & $\begin{array}{l}\text { Receptive vocabulary, receptive } \\
\text { grammar, sentence production, } \\
\text { rating of productive language) }\end{array}$ & PPVT, SETK3-5 & $\begin{array}{l}\text { Cooperation, aggression, } \\
\text { self-regulation }\end{array}$ & 4-point scale \\
\hline 11 & $\begin{array}{l}\text { Rose et al. } \\
\text { (2018b) }\end{array}$ & $3-5$ & 530 & German & $\begin{array}{l}\text { Receptive vocabulary, receptive } \\
\text { grammar, productive language, } \\
\text { home literacy activity }\end{array}$ & PPVT, SETK3-5 & $\begin{array}{l}\text { Cooperation, aggression, emotional } \\
\text { self-regulation }\end{array}$ & 4-point scale \\
\hline 12 & $\begin{array}{l}\text { Tan \& Dobbs- } \\
\text { Oates (2013) }\end{array}$ & 4 & 61 & English & $\begin{array}{l}\text { Expressive vocabulary, receptive } \\
\text { vocabulary, print awareness, } \\
\text { alphabet knowledge, print } \\
\text { conventions, construction of } \\
\text { meaning }\end{array}$ & PPVT, EVT, TERA & $\begin{array}{l}\text { Externalising behavior, internalising } \\
\text { behavior, approaches to learning, } \\
\text { interpersonal skills }\end{array}$ & DECA, BASC \\
\hline
\end{tabular}

PPVT=Peabody Picture Vocabulary Test; BNT=Boston Naming Test; EOWPVT-R=The Expressive One-Word Picture Vocabulary Test-Revised; BAS=British Ability Scale; TOLD-GU = Test of Language Development-Grammatical Understanding; ITPA-GC = Illinois Test of Psycholinguistic Abilities-Grammatical Closure; ERC=The Emotion Regulation Checklist; BASC=Behavior Assessment System for Children; DECA=Devereux Early Childhood Assessment; TERA=Test of Early Reading Ability; SETK35=Comprehensive German Language Development Test for 3-to-5-year-old children; CTRS=The Conners Teacher Rating Scale; ASPI=Adjustment Scales of Preschool Intervention. 


\section{국문초록}

\section{아동의 언어능력과 사회정서발달의 관계에 관한 메타분석}

김영태 · 강진경 · 김정아

이화여자대학교 언어병리학과

배경 및 목적: 사회정서는 아동의 발달에 중요한 요인이며, 언어능력은 사회정서발달과 밀접한 관계가 있다고 알려져 왔다. 본 연구는 메타분석을 통하여 아동의 언어능력과 사회정서발달의 관계를 살펴보고, 두 변수의 하위영역 간에도 어떠한 상관관계가 있는지를 분 석하고자 하였다. 언어능력은 수용언어, 표현언어, 초기 문해능력으로 나누고, 사회정서발달 변수는 외현적 행동, 내재적 행동, 사회적 기술, 자기조절로 구분하였다. 방법: 9개의 국내외 데이터베이스(Academic Search Complete, PsycINFO, Eric, PubMed, CINAHL Plus, ScienceDirect, RISS, DBpia, Kyobo Scholar)를 통해 포함 및 제외 기준을 적용하여 총 12 편의 문헌을 분석대상으로 선정하였고, Fisher's Z를 사용하여 효과크기를 산출하였다. 결과: 아동의 언어능력과 사회정서발달은 전체적으로 유의미한 상관관계를 보였다. 각 하위영역에서는 수용언어능력과 내재적 행동 및 자기조절, 표현언어능력과 내재적 행동 및 사회적 기술, 초기 문해능력과 사회적 기술 및 자기조절에서 유의미한 상관관계가 나타났다. 그러나 사회정서발달의 하위영역 중 외현적 행동은 언어능력의 전 하위영역과 유의미 한 상관관계를 나타내지 않았다. 논의 및 결론: 아동의 언어능력이 사회정서발달과 유의미한 관련이 있음을 확인할 수 있었다. 앞으로 언어중재를 통해 부정적인 사회정서는 감소시키고, 긍정적인 사회정서는 발달시킬 수 있는 방법을 모색할 필요가 있다.

핵심어: 수용언어, 표현언어, 초기 문해능력, 사회정서발달, 메타분석

본 연구는 2018년 대한민국 교육부와 한국연구재단의 지원을 받아 수행된 연구임(No. NRF-2018S1A3A2075274, NRF-2018S1A3A2075274).

\section{참고문헌}

김정아, 오세진, 최은정, 김영태, 성지은(2018). 시선추적장치를 활용한 읽기장애 아동의 텍스트 처리 특성에 관한 메티분석. Communication Sciences \& Disorders, 23(3), 597-608.

서윤(2014). 학교폭력 피해경험의 지속성 및 노출정도가 청소년의 사회정서발달에 미치는 영향. 청소년학연구, 21(6), 223-253.

오세진, 엄보라, 박채원, 성지은(2016). 실어증 환자를 위한 의미자질 이름대기 중재 효과에 관한 메타분석. Communication Sciences \& Disorders, 21(2), 310-323.

\section{ORCID}

김영태(https://orcid.org/0000-0003-1738-6862); 강진경(https://orcid.org/0000-0002-4431-6897); 김정아(https://orcid.org/0000-0003-4845-8187) 